\title{
Um exame de prática discursiva do trabalho de seleção de professores de línguas estrangeiras para o sistema público de ensino básico
}

\author{
Discursive practice of the work in admission exams for foreign language teachers \\ for the public basic education system
}

Del Carmen Daher

Universidade Federal Fluminense / CNPq - Niterói - Rio de Janeiro - Brasil

\begin{abstract}
$\diamond$
Resumo: Este artigo apresenta algumas considerações sobre a prática do concurso público que seleciona professores de línguas estrangeiras para o ensino básico. Para o estudo dessa prática, responsável pelo ingresso à carreira docente como servidor público, nos pautamos em aportes teóricos de uma perspectiva discursiva de base enunciativa (MAINGUENEAU, 1984, 1987, 2000) e contribuições advindas da Ergologia (SCHWARTZ, 1998, 2000), que consideram uma concepção ampliada de situação de trabalho (ROCHA, DAHER, SANT'ANNA, 2002). As reflexões apresentadas advêm do relato de atuação da pesquisadora em banca de concurso público e visam contribuir com discussões sobre o campo profissional do linguista e suas possibilidades de intervenção em questões sociais, em particular no que concerne a impasses e renormalizações vinculadas à realização desse trabalho.
\end{abstract}

Palavras-chave: Linguagem e trabalho; Concurso público para professores de língua estrangeira do ensino básico; Prática discursiva; Edital; Prova oral

\begin{abstract}
This paper presents some considerations on the practice of government admission exams for foreign language teachers for basic education in public school. For the study of such practice, which is responsible for entering the teaching career as a government employee, we part from the theoretical contribution of a discursive-enunciative perspective (MAINGUENEAU, 1984, 1987, 2000) and the contributions of the Ergology studies (SCHWARTZ, 1998, 2000) that takes into account a broaden conception of the work situation (ROCHA, DAHER, SANT'ANNA, 2002). The reflections presented in this paper come from the reporting of the researcher's participation as examiner in government admissions and aim at contributing to discussions about the professional field of linguists and the possibilities of intervention in social issues, particularly those regarding impasses and renormalizations linked to the performance of such work.
\end{abstract}

Keywords: Language and work; Government admissions exams for foreign language teachers for basic education; Discursive practice; Notice of Admission; Oral exams

\section{Introdução}

Para exercer o trabalho de professor em escolas dos sistemas públicos de ensino básico, no Brasil, à semelhança de qualquer outra modalidade de ingresso ao serviço público, é necessária a aprovação em concurso, conforme determina a Constituição Federal do país:

[...] a investidura em cargo ou emprego público depende de aprovação prévia em concurso público de provas ou de provas e títulos, de acordo com a natureza e a complexidade do cargo ou emprego, na forma prevista em lei, ressalvadas as nomeações para cargo em comissão declarado em lei de livre nomeação e exoneração [...]. (CONSTITUIÇÃO FEDERAL, 1988, Cap. VII, Art. 37, Inciso II)

A essa prática social, constituída a partir de exigência legal, é atribuído um caráter "democrático", por meio de qual se garantiriam as condições de igualdade 
aos candidatos num mesmo processo de seleção e se comprovariam, pelo exame, suas competências e aptidões para assumir ou não o cargo.

Enquanto prática institucional, o concurso público (doravante CP) exige o estabelecimento de etapas (planejamento e organização) e critérios de avaliação (o atendimento a exigências e processos legais; uma justificativa para a realização do concurso público; a designação dos membros da equipe responsável pelos trâmites administrativos e organizacionais; a elaboração de edital; o convite e a convocação da banca, assim como o acompanhamento dos trabalhos de caráter pedagógico; as inscrições, dentre outros). Além disso, deve zelar e responder pela legitimidade do processo de seleção profissional (pelo sigilo desde a elaboração e confecção das provas, a leitura crítica, a atribuição de pesos e medidas, a incorporação de ajustes até seu término) e pela convocação e autorização dos profissionais aprovados a trabalhar no âmbito público (divulgação dos aprovados, recursos, convocação, investidura no cargo, escolha da escola etc.).

Essa prática tão complexa, que atende a tantas e diversas finalidades, reúne uma multiplicidade de relações e uma rede de saberes, institui conexões que configuram uma determinada estrutura de sustentação, capaz de comportar e gerir esse sistema em suas diversas dimensões e interlocuções implicadas ao longo da realização do CP. Constitui (e é constituída) um fazer/dizer instituído sob uma aparência de uniformidade e impessoalidade que implica a projeção de uma imagem de custódia e zelo pelo que é público e pelo pleito democrático. Essa aparente unidade configura e cristaliza um sentido de credibilidade.

As considerações até aqui apresentadas parecem não dialogar ou não ter relação aparente com as constantes críticas em circulação feitas à qualidade da educação pública de nosso país e à atuação de professores "despreparados" para o trabalho de docência no ensino básico, constantemente encontradas na mídia, em pronunciamentos e entrevistas com políticos, nas falas de diversas autoridades, em reportagens, assim como em outras interações e espaços que integram nosso cotidiano. É interessante constatar, no entanto, que não se costuma encontrar nessas críticas nem referência à natureza e a problemas encontrados no trabalho pelo professor, nem à prática do $\mathrm{CP}$, responsável pela seleção desses docentes ${ }^{1}$. A questão nos intriga: por que não se menciona a necessidade de avaliar o $\mathrm{CP}$, tendo em vista ser por meio dele que se selecionam os profissionais para o trabalho de ensino? Não é uma pergunta a ser respondida neste artigo, mas ela nos tem provocado diversas indagações, às quais vimos buscando responder por meio de pesquisas ${ }^{2}$.

É necessário esclarecer que como professora formadora de professores de espanhol como língua estrangeira (doravante de ELE) e pesquisadora da área dos estudos da linguagem e do trabalho, sabemos a relevância da vinculação da formação de professores de línguas a exigências intrínsecas ao trabalho da docência no ensino básico. É preciso entender a licenciatura como uma possibilidade de intervenção e assumi-la como formação profissional (DAHER; SANT'ANNA, 2010) que requer conhecimentos acadêmicos, relação com a escola e com o contexto em que esta se insere, com suas políticas e trajetórias, para mencionar algumas questões, contrariando práticas e crenças que a configuram a partir de outros vieses.

A história da escola sempre foi contada como a história do progresso. Por aqui passariam os mais importantes esforços civilizacionais, a resolução de quase todos os problemas sociais. De pouco valeram os avisos de Ortega y Gasset - e de tantos outros - dizendo que esta análise parte de um erro fundamental, o de supor que as nações são grandes porque a sua escola é boa: certamente que não há grandes nações sem boas escolas, mas o mesmo deve dizer-se da sua política, da sua economia, da sua justiça, da sua saúde e de mil coisas mais. A escola cresceu nesta crença. E os professores acreditaram que lhes estava cometida a missão de arautos do progresso. Contra tudo e contra todos, se preciso fosse. (NÓVOA, 1998, p. 19-20)

Unissonante a esses autores, discordamos de crenças como as que atribuem ao trabalho do professor uma responsabilidade missionária e milagrosa. Essas colocações deslocam o foco e desconsideram a pertinência de discussões de diversas ordens acerca do modo como se articulam dispositivos, naturalizam práticas e constituem sentidos sobre o professor e seu trabalho.

Nosso posicionamento ético e epistemológico ante o trabalho com a formação de professores

requer compreender que construir conhecimentos e produzir transformações exige relacionar os saberes produzidos nas instâncias acadêmicas e os saberes instituídos nas experiências vividas pelas pessoas que atuam na atividade de professor de ELE. Isso quer dizer que é no encontro entre esses saberes que se torna possível pensar qualquer transformação. (DAHER; SANT'ANNA, 2010, p. 59)

\footnotetext{
Não se ouve falar na mídia, por exemplo, de um modo geral, fora das pseudopreocupações dos pleitos eleitorais, sobre: a sobrecarga de trabalho a que estão submetidos os trabalhadores da educação; as jornadas duplas (ou triplas); o excesso de alunos a serem atendidos em sala de aula; os salários incompatíveis com a natureza das atividades realizadas, insuficientes para uma sobrevivência digna; a impossibilidade de dispensa para realização de formações complementares; os incipientes ou mal gastos investimentos em Educação; a constituição de políticas públicas que em longo prazo resultem em mudanças efetivas.

2 "Concursos públicos para professores da rede pública de ensino: questões em exame" (UFF, CNPq PQ, 2011/01-2013/02) e "Práticas de linguagem e mundo do trabalho: exames de seleção de profissional" (PROCIÊNCIA Uerj/Faperj (2005/02-2008/01 e 2008/01-2009/01).
} 
Desde 2005, vimos desenvolvendo estudos ${ }^{3}$ voltados para a relação linguagem e trabalho, tendo como objeto de análise os concursos públicos que selecionam professores de línguas estrangeiras para o ensino básico. Entre os resultados de nossas pesquisas temos verificado que

além do "poder jurídico", [são privilegiados] saberes acadêmicos como os da gramática tradicional, e, ao mesmo tempo, ignoram-se outros saberes também fundamentais para a realização do trabalho na escola. [...] nenhum espaço é dado a discussões em torno de o que o professor precisa saber de fato para lidar com a realidade da sua prática (que não envolve só os limites da sala de aula). Essa relação entre poder e saber não se restringe ao universo da academia, mas circula também na escola, na mídia, na sociedade como um todo.

Da forma como vêm sendo constituídos os Concursos Públicos, constata-se a valorização de um profissional que não se vê examinado a partir de uma demonstração de capacidade teórica, reflexiva, crítica, autônoma, apto a lidar com as renormalizações exigidas em sua atividade de trabalho. Busca-se selecionar um profissional domesticado para identificar e repetir valores considerados relevantes por um determinado grupo. (DAHER; ALMEIDA; GIORGI, 2009, p. 85)

Esses resultados apontam, ainda, uma despreocupação com a constituição de uma memória das seleções, uma vez que, até bem pouco tempo atrás, as instituições promotoras do CP não garantiam a custódia desses exames e documentos, demonstrando o pouco valor que lhes é dado e inviabilizando a realização de estudos posteriores sobre esses processos. A "avaliação da avaliação" parece não interessar nem às instituições que realizam os concursos públicos, nem à comunidade em geral (que se submete a esses processos), menos ainda à comunidade acadêmica.

Neste artigo, traremos algumas reflexões e considerações a partir do relato de uma situação de trabalho na qual fomos convidadas a assumir a coordenação pedagógica de um concurso público para professor de ELE de um dos maiores sistemas de ensino municipal do Brasil. ${ }^{4}$ Tivemos, assim, instaurada a possibilidade de intervir no que até então se constituíra um objeto de pesquisa. Essa situação de trabalho impensada exigiria de nossa parte uma implicação com o CP de outra natureza, ou seja, permitiria o diálogo entre os resultados das pesquisas, o trabalho como professora formadora de professores, a experiência como professora do ensino básico e o trabalho de avaliar profissionais. Vivenciando uma situação de trabalho impensada, até então, por nossos aportes teóricos, já que coordenadora pedagógica - pesquisadora - professora estariam convocadas em um mesmo fazer, uma mesma atividade. Desta forma, o artigo configura-se a partir do esforço de trazer à reflexão questões de análises, impasses e renormalizações vinculadas à realização desse trabalho.

Os concursos para professores das disciplinas de Artes Plásticas, Artes Cênicas e Educação Musical, de Português, de História, de Matemática e de Língua Estrangeira (Espanhol), realizados para esse sistema de ensino em 2012, constituíram uma situação sui generis. À exceção do último mencionado, exigiram aprovação em: (1) prova objetiva (múltipla-escolha) sobre conteúdo específico da disciplina (para a qual concorrem à vaga de docentes),${ }^{5}$ de língua portuguesa e de fundamentos teórico-metodológicos e político-filosóficos da Educação constantes em edital; (2) prova discursiva (manuscrita) sobre conteúdo específico; (3) prova de títulos (aferidos apenas em caso de aprovação do candidato nas demais provas); e (4) prova de prática de aula (com entrega de planejamento de aula e realização de miniaula com duração de 15 a 20 minutos). Já, a seleção para docentes de língua estrangeira (espanhol) constou de (1) prova objetiva sobre conteúdo específico da disciplina, língua portuguesa e fundamentos teórico-metodológicos e político-filosóficos da Educação; (2) prova oral e (3) prova de títulos.

É sobre o entendimento dessa diferenciação nas provas de seleção que refletiremos neste artigo, por entender ser papel da universidade problematizar práticas como a do CP já que tem sob sua responsabilidade a formação dos futuros professores. Acredita-se ainda ser esta uma possível contribuição a estudos de práticas sociais, a partir da compreensão dos diversos discursos que as integram.

A partir do exposto, apresentamos, de forma breve neste artigo, considerações relativas: (1) ao que se entende como prova de prática de aula e prova oral nos concursos desse sistema de ensino; (2) a uma busca de sentidos sobre o que se caracteriza/pressupõe como necessidade para realização de modalidades de provas diferenciadas entre as demais disciplinas e a língua estrangeira; e (3) à identificação do que se espera que demonstre um professor de LE como desempenho na prova oral. No item 2 , incluímos explicações relativas à base teórica de apoio e no 3 , à análise do CP.

\footnotetext{
3 Integram essa vertente os grupos de pesquisa CNPq: Atelier, linguagem e trabalho (PUC-SP); PRÁTICAS de linguagem, trabalho e formação docente (UFF); e PraLinS - Práticas de Linguagem e Subjetividade (UERJ). Seus membros integram o GT ANPOLL Linguagem, Enunciação e Trabalho.

4 Embora os materiais trabalhados sejam públicos, por razões de preservação de sigilo, preferiu-se não identificar a mencionada rede.

5 No CP para Língua Portuguesa, em função da disciplina específica já ser sobre a Língua portuguesa, as questões objetivas foram sobre ela e sobre fundamentos teórico-metodológicos e político-filosóficos da Educação.
} 


\section{Enquadre teórico: o X da questão}

É preciso esclarecer que nossas vinculações acadêmicas se inscrevem num marco de pesquisa que a concebe a partir do diálogo com diversas disciplinas, saberes, instâncias, experiências e que considera as escolhas realizadas pelo pesquisador, suas implicações. Nosso entendimento é o de que nos situamos a partir de entrecruzamentos, condições de observações, de constatações que, a sua vez, resultam de possibilidades de saberes, que expressam e vinculam sentidos. Inúmeros são os confrontos, desconfortos e debates envolvidos nesse processo. É a partir deles que problematizamos a prática social do $\mathrm{CP}$ como objeto de estudo. Como analistas do discurso sabemos que

Problematização não quer dizer representação de um objeto preexistente, nem tampouco a criação pelo discurso de um objeto que não existe. $E$ E o conjunto das práticas discursivas ou não discursivas que faz alguma coisa entrar no jogo do verdadeiro e do falso e o constitui como objeto para o pensamento (seja sob a forma da reflexão moral, do conhecimento científico, da análise política etc.).(FOUCAULT, [1994]2010,p. 242)

Assim, e tendo como base pressupostos da Análise do Discurso, como o de que "não existe relação de exterioridade entre o funcionamento do grupo e de seu discurso, sendo preciso pensar, desde seu início, em sua imbricação (MAINGUENEAU, [1987] 1997, p. 55), recorremos à noção de "prática discursiva" (FOUCAULT, [1969] 2007) e à compreensão de que o "enunciado é sempre um acontecimento que nem a língua, nem o sentido podem esgotar inteiramente" (FOUCAULT, [1969] 2007, p. 31).

A linguagem integra o conjunto das práticas sociais, torna-as possíveis e ao mesmo tempo se faz possível a partir delas. Esta constituição situa-se no limite e não no interior do próprio discurso, já que qualquer enunciado, intrinsicamente, carrega as marcas de sua possibilidade de existência, considera "não a língua que o discurso utiliza não as circunstâncias em que ele se envolve, mas o próprio discurso enquanto prática" (FOUCAULT, [1969] 2007, p. 51-52). A esse respeito, afirma, ainda, Foucault:

Não podemos confundi-la [a prática discursiva] com a operação expressiva pela qual um indivíduo formula uma ideia, um desejo, uma imagem; nem com a atividade racional que pode ser acionada em um sistema de inferência; nem com a "competência" de um sujeito falante, quando constrói frases gramaticais; é um conjunto de regras anônimas, históricas, sempre determinadas no tempo e no espaço, que definiram, em uma dada época e para uma determinada área social, econômica, geográfica ou linguística, as condições de exercício da função enunciativa. (FOUCAULT, [1969]2007, p. 133)
Assim, a análise do modo pelo qual aparece determinado enunciado e não outro em seu lugar relaciona-se, segundo o autor, à força de saberes e de poderes que se inscrevem na história da sociedade ocidental.

O termo prática discursiva ${ }^{6}$, cunhado por Foucault (FOUCAULT, [1969]2007), é retomado e reconfigurado por Maingueneau como a "reversibilidade essencial entre as duas faces, social e textual, do discurso" ([1987] 1993, p. 56). Para este autor:

A noção de "prática discursiva" integra [...] por um lado, a formação discursiva, por outro, o que chamamos de comunidade discursiva, isto é, o grupo ou a organização de grupos no interior dos quais são produzidos, gerados os textos que dependem da formação discursiva. (MAINGUENEAU, [1987] 1993, p. 56)

Para o autor, a noção de discurso compreende não só “dispersão de textos, cujo modo de inscrição histórica permite definir como um espaço de regularidades enunciativas" (MAINGUENEAU, [1984] 2005, p. 15), mas também como condição per si de enunciabilidade, que implica: formas de (poder) dizer e silenciar, de estabelecer sentidos, posturas, procedimentos, sistemas de normas, apropriações, classificações. Ou seja, a partir de imbricações que lhe dão condições de/e determinam sua existência já que o discurso

não é nem um sistema de 'ideias', nem uma totalidade estratificada que poderíamos decompor mecanicamente, nem uma dispersão de ruínas passível de levantamentos topográficos, mas um sistema de regras que define a especificidade de uma enunciação. (MAINGUENEAU, [1984] 2005, p. 19)

Sistema esse que se materializa não só em formas de interlocução, em textos, mas nas práticas discursivas. E enquanto prática, modeliza, configura e corrobora saberes compartilhados por comunidades que semantizam discursos, por exemplo, sobre a formação e o trabalho do professor.

Como afirma Maingueneau ([1984] 2005, p. 16), as "unidades de um discurso constituem, com efeito, sistemas, sistemas significantes, enunciados e, nesse sentido, têm a ver com uma semiótica textual; mas também têm a ver com a história que fornece a razão para as estruturas de sentido que eles manifestam" e sustentam. Segundo explica Orlandi, tem a ver com "alguma coisa mais forte - que vem pela história, que não pede licença, que vem pela memória, pelas filiações de sentidos constituídos em outros dizeres, em muitas outras vozes, no jogo da língua, que vai se historizando" (ORLANDI, 1999, p. 32).

\footnotetext{
6 Inicialmente em seus estudos, Foucault recorre ao termo episteme, que é substituído, primeiramente, pela denominação dispositivo e, finalmente, referido como prática.
} 
Nossa pesquisa dialoga também com pressupostos teóricos advindos da perspectiva ergológica que estuda a atividade de trabalho, a partir da compreensão de que ela se constitui sempre como um debate de normas, singular, por meio do qual cada trabalhador recria o trabalho, posto que "o homem não se deixa totalmente comandar de fora, está, ao contrário, numa relação polêmica com o mundo das normas nas quais se encontra" (DURRIVE, 2011, p.49), confrontando sempre "o que exigem dele com o que ele exige de si mesmo" (DURRIVE, 2011, p.49).

Cabe ressaltar que diferente ao que é praticado por outros grupos ${ }^{7}$ multidisciplinares de pesquisa como esforço de pensar a complexidade de saberes investidos na atividade de trabalho, o nosso grupo ${ }^{8}$ está formado unicamente por linguistas. Esta configuração exige-nos deslocamentos que consideram o nosso campo de atuação, as possibilidades de intervenção e a visão de linguagem partilhada pelos pesquisadores de grupo. A partir de uma concepção de "situação de trabalho" ampliada (ROCHA; DAHER; SANT'ANNA, 2002), que se afigura para além da discussão originada a partir da observação e do que é dito pelo(s) trabalhador(es) ao(s) pesquisador(es), entendemos que o que se diz "sobre o trabalho" nas mais diversas práticas de linguagem, também inscreve referências ao trabalho e, de alguma forma, o incorpora e constitui, embora "regularmente [as falas sobre o trabalho sejam] vistas como desligadas da situação de trabalho stricto sensu" (ROCHA; DAHER; SANT'ANNA, 2002, p. 79). Compreendemos, assim, a situação de trabalho como configurada "a partir de toda uma rede de discursos proferidos, os quais se responsabilizam, em última instância, pelo(s) sentido(s) produzido(s)" (ROCHA; DAHER; SANT'ANNA, 2002, p.79) relativos a esse trabalho: as condições de enunciabilidade (FOUCAULT [1969]2007) que atravessam a realização de toda atividade de trabalho.

No próximo item, nos deteremos em considerações sobre o trabalho com o CP.

\section{Prova prática ou prova oral? Eis a questão}

As normas que nos impusemos desde o início do processo de seleção previam a determinação por traçar parâmetros para a constituição de um coletivo de trabalho envolvido com a formação docente e com o trabalho na educação básica; a preocupação com buscar formas de viabilizar, tanto a avaliadores como a avaliados, oportunidades para refletir sobre a importância e responsabilidade do trabalho de docência da língua estrangeira no ensino fundamental; e a possibilidade de considerar os resultados apontados nas pesquisas realizadas.
É importante ressaltar que ao aceitarmos o desafio da coordenação pedagógica do $\mathrm{CP}$, não estava decidido se os candidatos realizariam prova de prática de aula ou prova oral. A decisão dessa escolha foi comunicada somente após o aceite quando nos foi determinado seguir o modelo de prova oral adotado no CP de 2010, que selecionou professores de inglês como língua estrangeira.

O primeiro passo, adotado por nós, consistiu no convite feito à Prof ${ }^{\mathrm{a}}$ Vera Sant'Anna (UERJ), formadora de docentes de espanhol como língua estrangeira e também pesquisadora do grupo Atelier, para compartilhar o trabalho de coordenação pedagógica. Entre outros, os critérios adotados nessa decisão consideraram a experiência da professora-pesquisadora com reflexões sobre preceitos ergológicos e discursivos e o envolvimento com a formação docente e a educação básica.

Em parceria, demos início à análise da demanda: coordenar a seleção de professores de ELE realizada por meio de provas escritas de múltipla escolha (em português e em espanhol) e uma prova oral em língua estrangeira envolvendo 1.230 inscritos para 100 vagas. Elaborar edital de concurso. Realizar leitura crítica e mensurar pesos e medidas das questões da prova escrita. Elaborar prova oral, montar banca e gerir seu processo de realização. ${ }^{9}$

O primeiro impasse enfrentado deu-se com a determinação da demandante de exigir a realização de prova oral e não de prova de prática de aula, como o exigido aos professores das demais disciplinas. Buscar entender a questão constituiu-se como etapa necessária. Assim sendo, recorremos a editais anteriores para verificar como

\footnotetext{
7 (1) O grupo L\&T - Langage et Travail surgiu em 1987, em Paris, por iniciativa de um grupo de pesquisadores, sociólogos, linguistas e cientistas das organizações, interessados pelas relações entre as ciências sociais do trabalho e as ciências da linguagem. (2) O grupo APST-Analyse Pluridisciplinaire des Situation de Travail (Université de Provence - Aix-Marseille) começou, em 1984, a desenvolver projetos com o objetivo de confrontar os saberes teóricos universitários com experiências concretas, mas não ainda conceitualizadas, dos assalariados pertencentes a campos profissionais diversificados. O referido grupo está formado por profissionais de diferentes áreas do saber, entre elas a Filosofia, a Ergonomia, a Sociologia, a Economia e a Linguística. (3) O grupo ERGAPE - Ergonomie de l'Activité des Professionnels de l'Education é coordenado pelo Prof. Dr. René Amigues e conta com professores-pesquisadores do Instituts Universitaires de Formation des Maîtres (IUFM) de Aix-Marseille, entre eles Daniel Faïta e Frédéric Saujat, e conta com representantes das diferentes disciplinas implicadas na análise do trabalho. Suas pesquisas têm como foco a atividade de trabalho, o trabalho do professor e sua formação.

8 Os membros do grupo integram o GT Anpoll Linguagem, Enunciação e Trabalho e os seguintes GRPes's Atelier-Linguagem e trabalho (PUC-SP/ CNPq), PRÁTICAS de linguagem, trabalho e formação docente (UFF/ CNPq), Grupos de pesquisa Práticas de linguagem e subjetividade PraLinS (UERJ/CNPq).

9 Cabe esclarecer que em relação à elaboração da prova escrita, a composição da banca foi de responsabilidade da demandante e contou também com a participação de membros do nosso grupo de pesquisa, os professores doutores Maria Cristina Giorgi e Fábio Sampaio de Almeida.
} 
os documentos referiam essas modalidades de provas. Como forma de facilitar a leitura, optamos por identificar os fragmentos extraídos de diferentes editais pelas siglas: LECP2010, para o concurso de língua estrangeira (inglês), LECP2012 para o de língua estrangeira (espanhol) e CP2112, para as demais disciplinas.

Como síntese das atribuições do professor do ensino fundamental, os editais prescrevem:

- responsabilizar-se pelo bom andamento do trabalho dos alunos sob sua responsabilidade;

- participar do planejamento curricular da Escola;

- planejar suas atividades como regente de turma, visando a um bom desenvolvimento funcional;

- acompanhar e avaliar o desempenho do aluno, propondo medidas para melhor rendimento e ajustamento do mesmo em consonância com a Coordenação Pedagógica;

- manter atualizado o material de registro de desempenho do aluno, obedecendo a normas e prazos estabelecidos;

- utilizar as horas complementares em atividades pedagógicas inerentes à sua função de docente;

- atender às determinações da Escola, quanto à observância de horário e convocações;

- manter-se em permanente atualização pedagógica, visando ao aperfeiçoamento profissional;

- executar quaisquer outros encargos semelhantes e pertinentes à categoria funcional.

Em consonância com a Lei de Diretrizes e Bases da Educação Nacional no 9394, de 20/12/96, são ainda atribuições do cargo:

- ministrar os dias letivos e horas-aula estabelecidos;

- participar, integralmente, dos períodos dedicados ao planejamento, à avaliação e ao desenvolvimento profissional;

- colaborar com as atividades de articulação da escola com as famílias e a comunidade. (CP2112; LECP2012; LECP2010)

Todas essas prescrições, embora redutoras ao considerar o complexo trabalho docente, são tarefas que estão sob a responsabilidade dos professores e integram suas rotinas. Elas estão, de alguma forma, em consonância com os critérios de avaliação propostos para as provas de prática de aula, nas quais afirma-se esperar como comprovação de desempenho do candidato que ele demonstre, em sua exposição, (1) conhecimento do assunto, (2) adequação no uso da linguagem ao ano de escolaridade, (3) capacidade de síntese, (4) preparo para o desenvolvimento da aula, e (5) elaboração de planejamento da aula" (CP2112).

No entanto, ao não se exigir que os professores de língua estrangeira realizem a prova de prática de aula, levanta-se a possibilidade de que essa comprovação possa/venha a ser feita por meio da prova oral. E suscitanos diversas expectativas acerca dos sentidos que atravessam o entendimento do que é ser professor de língua estrangeira na escola de ensino fundamental. $\mathrm{O}$ que nos aponta essa decisão? O que está sendo silenciado, interditado, não dito?

Alguns questionamentos se delineiam. As provas discursivas e de práticas de aula a que são submetidos os candidatos das demais disciplinas se realizam em língua portuguesa e consideram além da demonstração de conhecimentos, a da "coerência, coesão, clareza e objetividade, bem como a utilização correta do vocabulário e das normas gramaticais segundo o Novo Acordo Ortográfico (CP2012)" no domínio dessa língua. Essas provas não são realizadas pelos candidatos de língua estrangeira.

Essa diferenciação na seleção para o trabalho num mesmo nível de ensino é no mínimo provocadora de muitas reflexões. Por um lado perguntamos: por que o professor dessa disciplina não precisa demonstrar domínio em língua materna da expressão escrita (prova discursiva) e nem da oral (prova de prática-didática) como os demais docentes? Como fica garantido seu domínio na língua portuguesa? Por que não lhe é necessário comprovar esse domínio? O que autoriza a dispensa das provas discursiva e de prática de aula em língua materna? O que isso aponta? A comprovação de que essa demonstração não é necessária? Que entendimentos se podem pressupor a partir da constatação de que ele precisa apenas demonstrar ter competência oral e leitora ${ }^{10}$ na língua estrangeira para poder assumir o trabalho no ensino fundamental? E a produção escrita? Se não há prova discursiva, como comprovar essa suficiência? Por outro lado, por que uma prova oral e não uma prova de prática de aula realizada em língua estrangeira? Mais alguns impasses.

Movidas por todas essas indagações nos voltamos para as considerações relativas à prova oral de inglês apresentadas no edital de LECP2010. Como se configura uma prova oral que seleciona professores de língua estrangeira? O que se espera que demonstre esse professor como desempenho por meio da prova oral? A essas questões procuraremos responder.

No item "VII Das provas" do edital LECP2010 uma observação se destaca: a atribuição e distribuição dos pontos das provas, conforme se pode verificar a seguir:

10 Não foi realizada, ainda, a análise das provas objetivas do LECP2010 e
LECP2012. 
Quadro com atribuição de pontos por questão e mínimos para aprovação

\begin{tabular}{|c|c|c|c|c|c|c|}
\hline Tipo de prova & Conteúdo & $\begin{array}{c}\mathrm{N}^{\circ} \text { de } \\
\text { questões }\end{array}$ & $\begin{array}{l}\text { Pontos por } \\
\text { questão }\end{array}$ & $\begin{array}{c}\text { Total em } \\
\text { pontos }\end{array}$ & $\begin{array}{l}\text { Mínimo em pontos } \\
\text { para habilitação } \\
\text { por conteúdo }\end{array}$ & $\begin{array}{l}\text { Mínimos em pontos } \\
\text { para habilitação }\end{array}$ \\
\hline \multirow[b]{3}{*}{ OBJETIVA } & Específica da Disciplina & 35 & 2,0 & 70,0 & 14,0 & \multirow[b]{3}{*}{72,0} \\
\hline & Língua Portuguesa & 15 & 2,0 & 30,0 & 6,0 & \\
\hline & $\begin{array}{l}\text { Fundamentos } \\
\text { Teórico-Metodológicos } \\
\text { e Político-Filosóficos da } \\
\text { Educação }\end{array}$ & 10 & 2,0 & 20,0 & 4,0 & \\
\hline ORAL & & & & 100,0 & & 50,0 \\
\hline TÍTULOS & & & & 30,0 & & \\
\hline
\end{tabular}

A prova oral não possui conteúdo prévio especificado no edital (desnecessário?), mas tem estipulado o valor máximo 100 pontos, enquanto a prova objetiva, com conteúdos específicos constantes do Anexo do edital, corresponde em sua totalidade a 120 pontos repartidos entre a prova Específica da Disciplina (Língua estrangeira - Inglês), 70 pontos, a de Língua Portuguesa, 30 pontos, e a de Fundamentos Teórico-Metodológicos e PolíticoFilosóficos da Educação, 20 pontos. A pontuação prevista para a prova oral é maior do que a da prova objetiva específica da disciplina, comprovando a maior valorização ao perguntado e respondido oralmente em detrimento de saberes acadêmicos e da experiência, avaliados por escrito, saberes necessários e específicos ao desempenho como professor de ensino básico.

Ao verificarmos os detalhamentos que constavam no edital, deparamo-nos com uma única orientação ao candidato com relação a procedimentos a serem seguidos na avaliação oral, a exposta no item 3.1:

\section{Da prova oral}

3.1 Será avaliada a expressão oral do candidato considerando: a adequação e o uso proficiente das estruturas linguísticas e do léxico, conforme a situação discursiva em questão; a fluência e os aspectos fonético-fonológicos da produção. (LECP2010)

Todos os demais subitens contêm informações de natureza jurídico-administrativa, tais como a referência a local, dia e hora da realização da prova, os critérios de desempate e a impossibilidade de recurso. A adequação, proficiência e fluência na língua estrangeira precisam ser provadas, ainda que não saiba o candidato (nem ninguém), sob quais condições se dará a interação, para que dinâmica deverá estar preparado ou especificações relativas ao que será perguntado.

Dessa forma, solicitamos à demandante acesso ao material utilizado na realização da prova oral pela banca do concurso de 2010. Foram-nos entregues cadernos impressos em inglês nos quais constam o total de tempo da prova, 10 a 12 minutos, as etapas a serem seguidas, organizadas em três partes e os exemplos de perguntas a serem utilizadas.

À primeira parte, denominada "Entrevista", foram atribuídos 3 minutos máximos de duração. Durante os quais, o candidato recebia o caderno com a roteirização escrita da fala da banca (Ex.: "Good morning/afternoon. I'm__ and this is__ ”), das perguntas pessoais que lhe seriam feitas (Ex.: "And what's your name, please?", "First of all, we'd like to known a few things about you. Where are you from__?, e "Where do you live?") e uma relação de cinco perguntas, entre as quais o candidato deveria escolher três (Ex.: What's your neighborhood like?, If you could, what would you change in it?, What do you do? What do you like most about your job/studies?, Is there anything you don't like about your job/studies? e "How do you spend your free time?).

A segunda destinava 1 minuto para apresentação da explicação, o tempo para leitura e para optar pelo tópico a ser respondido. O candidato deveria escolher um entre dois e, ao falar sobre o tópico escolhido, utilizar as sugestões que lhe eram indicadas. Cabia à banca informar ao candidato que não seria necessária na exposição nenhuma remissão a uma teoria específica sobre ensino de línguas, podendo desenvolver o tópico a partir de sua experiência/opinião (Ex.: "What factors might affect students?"; "lake of motivation" / "unsuitable materials"/ "insufficient practice"), dispondo de 4 a 5 minutos para sua fala.

A parte 3, denominada "Discussão", consistia na explanação sobre um tema, como por exemplo, "saúde", de 3 a 4 minutos, nos quais o candidato deveria falar a partir de três perguntas escolhidas entre seis que lhe eram apresentadas. A recomendação à banca era a de que interferisse se achasse apropriado, acrescentando perguntas como "Why (not)?", "How".

Consideramos que analisar práticas discursivas relacionadas ao mundo do trabalhador da Educação - e as provas de seleção de professores de ELE inscrevemse nessas práticas -, de alguma forma, garantem uma maior visibilidade sobre a complexidade do trabalho 
do professor, o que dele se espera, assim como do atual momento desse ensino e da trajetória na qual ele se ancora. $\mathrm{O}$ entendimento de que uma prova oral, organizada nos moldes que acabamos de apresentar, é suficiente para permitir/garantir a demonstração de preparo profissional para o trabalho em escolas é iludir a todos: candidato, comunidade escolar e população em geral. Constitui-se apenas como uma demonstração de que o professor sabe responder ao que lhe é perguntado pela banca, não o que efetivamente possa estar vinculado a seu trabalho e aos conhecimentos que esse trabalho exige. A que outras finalidades se destina o CP? A atender a aspectos jurídicos, político-eleitorais ou de divulgação governamental?

Como intervir numa prática de seleção que promova novos discursos e agires sobre o trabalho do docente na escola? Como romper com crenças /ilusões de que para ser professor de uma língua estrangeira basta saber minimamente comunicar-se oralmente nessa língua, ainda que não se seja capaz de ministrar uma aula e, de gerir o trabalho de aprendizagem dos alunos, valendose da língua estrangeira como forma de acesso à cultura do outro e à própria cultura? Em que medida perguntas como as efetuadas na prova oral de inglês garantem minimamente a um candidato a possibilidade colocarse frente a questões pertinentes à atividade docente, a reflexões sobre as necessidades da comunidade escolar? Sabemos que o trabalho não é antecipável, mas, no caso do trabalho docente, o CP constitui-se como uma das situações de trabalho vividas pelo professor.

Por um lado o estudo do edital e da prova oral nos permitiu uma maior visibilidade sobre um dispositivo de poder, que se constitui a partir de uma rede de relações entre esses textos, entre o discursivo e não discursivo, entre o que é possível e acorde com o que deve/pode ser enunciado e legitimado pela instituição. Por outro lado, o enfrentamento com essas verdades naturalizadas, exigiu-nos conjugar esforços para promover novos nexos, de forma a constituir mudanças que considerassem a necessidade e peculiaridade do trabalho de ensino.

Tomando como ponto de partida o modelo de prova oral proposto pela demandante e as exigências que nos impúnhamos em buscar constituir uma alternativa que valorizasse o conhecimento profissional, propusemos algumas mudanças e elaboramos a parte do edital de concurso relativa à língua estrangeira (espanhol). Nas negociações com a instituição não nos foi possível realizar a prova de prática de aula, porém conseguimos permissão para incluir no edital a descrição dos procedimentos a serem seguidos pelo candidato na realização da prova oral e vinculá-la aos conteúdos do programa. Conteúdos estes selecionados de forma que viessem a permitir a articulação com situações de sala de aula do ensino fundamental. Assim, foram estabelecidos o programa (Anexo I), a bibliografia ${ }^{11}$ a nova organização da prova oral e estabelecidos os critérios para composição da banca arguidora.

Para a constituição de duplas de banca responsáveis pela avaliação oral, a coordenação teve como premissa buscar a aproximação entre experiências de natureza diferente: de um lado, professores universitários de instituições públicas de ensino superior formadores de professores de ELE e, de outro, professores de ELE que já atuassem no sistema público de ensino básico (com titulação de doutor ou mestre e, no caso de vir a ser necessário, de especialista). Esses profissionais com atuações em diferentes âmbitos educacionais trabalharam em pares durante a avalição.

Para a organização da prova, foi pensada uma dinâmica que permitisse às bancas avaliar o candidato de forma a que este pudesse demonstrar coerência entre a sua exposição sobre a questão teórica sorteada e a adequação dessa proposta a uma determinada configuração de situação de sala de aula.

Partimos da concepção de que o professor tem que demonstrar as suas capacidades de desenvolvimento do trabalho, pelo modo como relaciona o ponto sorteado a questões propostas pela banca. Demonstrando em língua estrangeira, não só seu domínio sobre essa língua, como também ser capaz de fazer correlações entre o teórico e sua relação/adequação a situações de ensino.

Conforme o edital, a organização da prova foi a seguinte:

\section{DA PROVA ORAL}

3.1 A prova oral constará de dois momentos. No primeiro, o candidato, diante da banca, sorteará um dentre os temas incluídos no programa específico da disciplina (Anexo I) e deverá fazer sua exposição oral em língua espanhola. Após esta exposição, deverá responder a três perguntas propostas pela banca, relacionadas ao mesmo tema.

3.2 A prova oral terá duração total de $10(\mathrm{dez})$ minutos, distribuídos da seguinte forma: 5 (cinco) minutos para a exposição oral inicial e 5 (cinco) minutos para as três respostas às perguntas efetuadas pela banca.

3.3 A avaliação do candidato na prova oral considerará a adequação:

- do tratamento dado ao tema, levando em conta sua relação com a sala de aula no ensino fundamental;

- do uso da língua espanhola ao respectivo contexto interacional;

- do desempenho oral no que diz respeito à pronúncia, fluência, clareza e coerência na exposição de ideias.

3.4 Serão convocados à Prova Oral todos os candidatos aprovados na prova objetiva;

3.5 Não haverá recurso contra o resultado da Prova Oral. (LECP2012)

\footnotetext{
${ }^{11}$ A elaboração do programa e seleção da bibliografia contou com a participação dos elaboradores da prova escrita e, naturalmente, da equipe técnico-administrativa da demandante.
} 
Tendo em vista a necessidade de contemplar tão variados itens do programa e que todos os candidatos respondessem questões semelhantes, escolhidas em ordem diferente, foi elaborado um quadro com um total de nove perguntas, organizadas em três linhas de três colunas, distribuídas de forma semelhante ao jogo da velha (Anexo II), o que possibilita constituir variados percursos, em função do tema sorteado e da sequência que se desenhasse, no momento, pela banca.

Os critérios de avaliação consideraram: o recorte dado ao tema sorteado, a conformidade da abordagem desse tema, tendo em vista a sala de aula do ensino fundamental; o domínio da linguagem acadêmica à situação de interação; a adequação da resposta dada a cada uma das três perguntas; a pronúncia, a fluência, a clareza e a coerência no exposto.

Ao longo de todo o processo do LECP2012, incitadas pelos valores ergológicos, conferimos à situação de avaliação um entendimento de que nela se realizava uma complexa conjunção de atividades de trabalho. Atividades essas constituídas por relações polêmicas, pelo debate de normas, por confrontos e exigências impostas a cada um desses trabalhadores, por um outro ou por si mesmos.

$\mathrm{Na}$ linguagem se constitui a atividade de trabalho do professor (seja na função de banca, seja na de candidato). Ao falar sobre como seria o seu trabalho, o candidato trabalha, no aqui agora da interação, realiza/vive o trabalho da prova. Isso se dá por meio da linguagem, de escolhas, recorrendo a "formulações que repetem, recusam e transformam outras formulações" (MAINGUENEAU, [1987] 1993, p. 118). Legitimando "vozes" e "saberes", que não só falam sobre o que é o trabalho do professor, como também configuram a imagem desse trabalhador.

Assim, no plano do prescrito, concebemos uma proposta de prova oral que provocasse com a primeira questão a fala sobre um saber teórico, em decorrência da pergunta sorteada. Com as demais perguntas, condições para que o candidato constituísse as adequações entre tal tema e essa teoria e propusesse possíveis tarefas a serem pensadas como situações de sala de aula.

\section{Considerações inconclusas}

O propósito deste artigo foi problematizar a prática social CP para professores de língua estrangeira dos anos finais do ensino fundamental de um dos sistemas de ensino público brasileiro, refletir sobre contribuições possíveis do trabalho do linguista e comentar inquietações e impasses vividos ao longo desse processo.

$\mathrm{O}$ relato requer desdobramentos, que não foram possíveis de contemplar nos limites deste artigo, mas aponta a relevância de estudos voltados para as práticas de seleção institucionalizadas, de forma a que possam ser desnaturalizadas e promovam a seleção de profissionais que precisem demonstrar conhecer saberes acadêmicos e da experiência intrínsecos às atividades de trabalho do professor e não apenas que sabe se comunicar de forma elementar em língua estrangeira.

As análises comprovam a necessidade de avaliar a avaliação.

\section{Referências}

BRASIL. Lei de Diretrizes e bases, no 9394, de 20 de dezembro de 1996.

BRASIL. Constituição da República Federativa do Brasil de 1998.

DAHER, Del Carmen. Discurso e atividade de seleção de professores. Moara. Estudos Linguísticos, Programa de PósGraduação em Letras/Universidade Federal do Pará, n. 38, p. 140-158, jul.-dez. 2012. Disponível em: <http://www. periodicos.ufpa.br/index.php/moara/issue/view/Revista $\% 20$ Moara/showToc $>$.

DAHER, Del Carmen. Prácticas discursivas de selección de profesores de español como lengua extranjera la educación básica. Hispanista, v. XII, n. 47, 11 p., out.-nov. 2011. Disponível em: <http://www.hispanista.com.br/artigos $\% 20$ autores $\% 20 \mathrm{e} \% 20 \mathrm{pdfs} / 365$.pdf $>$.

DAHER, Del Carmen; SANT'ANNA, Vera Lucia de Albuquerque. Formação e exercício profissional de professor de língua espanhola: revendo conceitos e percursos. In: BARROS, Cristiano Silva de; COSTA, Elzimar Goettenauer de Marins (Org.). Explorando o ensino. Brasília: Ministério da Educação, Secretaria de Educação Básica, v.16, 2010, p. 55-68. Disponível em: <http://www.portal.mec.gov.br/index.php?option=com docman\&task $=$ doc $>$.

DAHER, Del Carmen. Formación de profesores de español como lengua extranjera en Brasil: de otium cum dignitate a profesional de la escuela de enseñanza básica. Revista redELE., v.1, p.1-15, 2010. Disponível em: <http://www.educacion.es/ redele/Biblioteca2010_2/index.shtml>.

DAHER, Del Carmen; ALMEIDA, Fabio Sampaio. Selección de docentes de español como lengua extranjera: pruebas de ingreso al magisterio público de Rio de Janeiro. Approaches to Critical Discourse Analysis. Valencia: Universitat de València Servei de Publicacions, 2005. p. 1-27.

DAHER, Del Carmen; GIORGI, Maria Cristina; ALMEIDA, Fabio Sampaio A prática do concurso público para professores: uma seleção para o trabalho? In: DAHER, Del Carmen; GIORGI, GIORGI, Maria Cristina; RODRIGUES, Isabel Cristina. (Org.). Trajetórias em enunciação e discurso: práticas de formação docente. São Carlos: Claraluz, 2009. p. 77-88.

DURRIVE, Louis. A atividade humana, simultaneamente intelectual e vital: esclarecimentos complementares de Pierre Pastré e Yves Schwartz. Trab. Educ. Saúde, Rio de Janeiro, v. 9, supl. 1, p. 47-67, 2011. Disponível em: <www.scielo.br/pdf/tes/ v9s1/03.pdf $>$.

FOUCAULT, Michel. A arqueologia do saber. Tradução de Luiz Felipe Beata Neves. Rio de Janeiro: Forense Universitária, [1969] 2007. 
FOUCAULT, Michel. A verdade e as formas jurídicas. Tradução de Roberto Cabral de Melo Machado e Eduardo Jardim Morais. Rio de Janeiro: NAU/PUC, 1996.

FOUCAULT, Michel. Ditos e escritos II: Arqueologia das ciências e história dos sistemas de pensamento. Rio de Janeiro: Forense Universitária, 2005.

GIORGI, Maria Cristina. Seleção para a rede pública estadual de ensino: o que se espera do professor de língua estrangeira? Dissertação (Mestrado) - Universidade do Estado do Rio de Janeiro, Rio de Janeiro, 2005. 136p.

MAINGUENEAU, Dominique. Novas tendências em análise do discurso. Tradução de Freda Indursky. Campinas: Pontes, [1987] 1997.

MAINGUENEAU, Dominique. Gênese dos discursos. Tradução de Sírio Possenti. Curitiba: Criar Edições, [1984] 2005.

NÓVOA, Antônio. O passado e o presente dos professores. In: NÓVOA, Antônio (Org.). Profissão professor. Porto: Porto, 1998. p. 19-20.

ORLANDI, Eni. Análise de discurso: princípios \& procedimentos. Campinas: Pontes, 1999.

REVUE HISTOIRE DE L'EDUCATION. L'examen. Èvaluer, sélectionner, certifier. CVIe-XX siécles, n. 94, maio 2002.

ROCHA, Décio; DAHER, Del Carmen; SANT'ANNA, Vera Lucia de Albuquerque. Produtividade das investigações dos discursos sobre o trabalho. In: SOUZA-E-SILVA, Maria Cecília Pérez; FAÏTA, Daniel. Linguagem e trabalho: construção de objetos de análise no Brasil e na França. São Paulo: Cortez, 2002. p. 77-91.

SANT'ANNA, Vera Lucia de Albuquerque; SOUZA-E-SILVA, Maria Cecília Pérez. Trabalho e prescrição: aproximações ao problema a partir dos estudos da linguagem. Revista Matraga. Rio de Janeiro, v. 14, n. 20, p. 77-99, jan.-jun. 2007.

SCHWARTZ, Yves; DURRIVE, Louis. Trabalho e ergologia: conversas sobre a atividade humana. Tradução de Jussara Brito e Milton Athayde (Org.). Niterói: Editora da UFF, 2009.

VIVONI, Renata. Interlocução seletiva: análise de provas para seleção de docentes - A construção discursiva do perfil de profissional professor. Rio de Janeiro, 113 p. Dissertação (Mestrado em Letras, área de concentração em Linguística) Instituto de Letras, Universidade do Estado do Rio de Janeiro, 2003.

ZOUAIN, Deborah Moraes. Escolas de governo e escolas de serviço público: limites e problemas. Estudo de caso da Fundação Escola do Serviço Público do Estado do Rio de Janeiro (FESP/RJ) e Fundação da Administração Pública do Estado de São Paulo (FUNDAP). In: VIII Congreso Internacional del CLAD, outubro, Panamá, 2003. Disponível em: <unpan1. un.org/intradoc/groups/public/documents/CLAD/clad0047444. pdf $>$.

\section{ANEXO I PROGRAMA}

1. Políticas linguísticas de ensino de línguas estrangeiras no Brasil.

2. LDB $9394 / 96$ e documentos orientadores do ensino de língua estrangeira no ensino fundamental: PCN-LE do ensino fundamental; Multieducação: temas em debate, Língua estrangeira no ensino fundamental; Orientações Curriculares - áreas específicas.

3. Linguística aplicada e o papel do ensino de língua estrangeira na educação fundamental.

4. Articulação entre teorias linguísticas, teorias de aprendizagem e abordagens pedagógicas de ensino de língua estrangeira.

5. Especificidades do ensino de língua espanhola no ensino fundamental.

6. Variantes da língua espanhola e pluralidade cultural no mundo contemporâneo: questões identitárias no ensino de língua espanhola no ensino fundamental.

7. Análise linguístico-discursiva de textos de diversos gêneros e sua aplicabilidade no ensino fundamental.

8. Ensino da leitura em língua espanhola no ensino fundamental.

9. Ensino da escrita e da oralidade em língua espanhola no ensino fundamental. 
ANEXO II

QUADRO COM PERGUNTAS DA PROVA ORAL DE ESPANHOL

\begin{tabular}{|c|c|c|c|c|c|}
\hline \multirow{2}{*}{\multicolumn{2}{|c|}{$\frac{\text { (2 MINUTOS) }}{\text { Pergunta } 1}$}} & \multicolumn{4}{|c|}{ (3 MINUTOS) } \\
\hline & & \multicolumn{2}{|r|}{ Pergunta 2} & \multicolumn{2}{|r|}{ Pergunta 3} \\
\hline A & $\begin{array}{l}\text { A partir de lo presentado por Ud. sobre el } \\
\text { tema sorteado, exponga dos elementos } \\
\text { clave o conceptos que considere como } \\
\text { básicos y que el profesor de español } \\
\text { como lengua extranjera no puede } \\
\text { desconocer. Fundamente su elección. }\end{array}$ & D & $\begin{array}{l}\text { Presente dos criterios que fundamenten } \\
\text { una elección de textos, relacionados } \\
\text { al tema sorteado, que puedan ser } \\
\text { trabajados en clases de enseñanza } \\
\text { fundamental. Justifique esa elección. }\end{array}$ & G & $\begin{array}{l}\text { Proponga dos actividades relacionadas } \\
\text { a su selección de textos. }\end{array}$ \\
\hline B & $\begin{array}{l}\text { El tema sorteado por Ud. crea } \\
\text { expectativas sobre lo que debe ser la } \\
\text { relación entre profesor de ELE y alumno } \\
\text { de la enseñanza fundamental. Presente } \\
\text { dos criterios para distinguir la naturaleza } \\
\text { de esa relación en la escuela y en un } \\
\text { curso libre. }\end{array}$ & E & $\begin{array}{l}\text { Apunte dos posibles dificultades para } \\
\text { tratar el tema presentado por usted } \\
\text { en clases de ELE de la enseñanza } \\
\text { fundamental. }\end{array}$ & $\mathbf{H}$ & $\begin{array}{l}\text { A partir de lo presentado por Ud. } \\
\text { sobre el tema sorteado, indique dos } \\
\text { posibilidades para enfocar ese tema } \\
\text { en clases de ELE de la enseñanza } \\
\text { fundamental con la finalidad de } \\
\text { contribuir para la formación de un } \\
\text { alumno crítico. }\end{array}$ \\
\hline C & $\begin{array}{l}\text { A partir de lo presentado por Ud. sobre } \\
\text { el tema sorteado, exponga dos posibles } \\
\text { articulaciones entre ese tema y los } \\
\text { materiales didácticos que se suelen } \\
\text { utilizar en clase de ELE en la enseñanza } \\
\text { fundamental. }\end{array}$ & $F$ & $\begin{array}{l}\text { Presente dos supuestos teóricos que } \\
\text { fundamentarían su clase de ELE al } \\
\text { tratar del tema presentado. }\end{array}$ & I & $\begin{array}{l}\text { Exponga una actividad que Ud. } \\
\text { propondría para profundizar en el } \\
\text { tema sorteado en clase de enseñanza } \\
\text { fundamental. }\end{array}$ \\
\hline
\end{tabular}

Recebido: 10 de dezembro de 2013

Aprovado: 15 de janeiro de 2014

Contato: deldaher@terra.com.br 